\title{
Chandelier and interfascicular neurons in the adult mouse piriform cortex
}

\author{
Jorge A. Larriva-Sahd* \\ Instituto de Neurobiología, Universidad Nacional Autónoma de México, Querétaro, México
}

\section{Edited by:}

Larry W. Swanson, University of

Southern California, USA

Reviewed by:

Charles E. Ribak, University of

California Irvine, USA

Javier Defelipe, Cajal Institute, Spain

Alfonso Fairén, University Miguel

Hernandez, Spain

*Correspondence:

Jorge A. Larriva-Sahd, Instituto de

Neurobiología, Campus Universidad

Nacional Autónoma de México-

Universidad Autónoma de Querétaro,

Boulevard Juriquilla 3002, Querétaro,

CP 76230, México.

e-mail: jlsneuro@unam.mx
The structure of two neuron types native to the adult mouse piriform cortex (PC) is described. The first cell, termed an interfascicular neuron (IFN), lies between the axon fascicles of layer I. The IFN axon divides dichotomously and daughter fibrils run horizontally in the domain of layer la. The frequent apposition of the IFN axon to distal dendrites of the underlying pyramidal cells suggests an en passage synaptic interaction with them. A second neuron observed in layer II, or less frequently in layer III, matched in most respects the structure of the chandelier cell (CC) described elsewhere in the neo- and archi-cortex. In the PC, chandelier cells (PC-CC) display the following peculiarities. First, the PC-CC axonal field distributes in the neuropil of layers II and III and candlesticks are in close apposition to the initial axonal segment of the pyramidal cell, although somatic interactions cannot be rule out. Second, the PC-CC ascending dendrites pierce layer I, receiving short collaterals and boutons en passage from the olfactory axons therein. The possible role of IFN's and PC-CC and their interactions with the adjacent cells is discussed in the broad context of the cellular organization of the PC.

Keywords: neurons, primary olfactory cortex, neuropil, cytology

\section{INTRODUCTION}

The cytological organization of the piriform cortex (PC) has been the subject of numerous Golgi studies. Perhaps the first detailed work on the primary olfactory cortex was that performed by Calleja (1893) a young Ramón y Cajal (1904) protégé and by himself . In these studies utilizing prepubertal rodents and carnivores, the PC was defined for the first time as the "cerebral cortex covered by the external root" (i.e., lateral olfactory tract) and was divided into five layers, from pia to white matter: fibrillar zone, molecular layer, layer of small and large pyramids, plexiform or polymorph layer, and white matter. It was also found that olfactory fibers arising in the olfactory bulb and running in the fibrillar zone collateralize to resolve in the molecular layer of the PC. To Camilo Golgi's earlier description of principal cells (cellule gangliari, Golgi, 1885), Calleja further depicted assorted pyramidal cells bearing short apical or paired dendrites and sets of profusely ramified basilar dendrites. Modified pyramids were also documented and included bi-horn-, spindle-, triangular-, and crescent-shaped cells. Later O'Leary (1937), a Lorente de Nò disciple, made the first systematic study in the newborn and prepubertal mouse PC describing the pyramidal cell axon and collaterals and featured seven classes of interneurons. In this study, several types of interneurons were first classified based on their location and the extent of both dendritic and axonal fields. Further, O'Leary documented the existence of interneurons with ascending axons resembling those of Martinotti cells found in the neocortex (see Wang et al., 2004). In his memorable monograph Valverde (1965) highlighted six types of interneurons, utilizing primarily the prepubertal mouse brain. The first systematic study made in the adult mammalian brain was performed by Haberly (1983), who recognized nine types of interneurons classified primarily on the bases of their somatodendritic characteristics. Although earlier works (Haberly, 1983) and recent immunohistochemical studies (Zhang et al., 2006; Gavrilovici et al., 2010; Suzuki and Bekkers, 2010a,b) have described native neurons in the superficial layer of the PC, their somatodendritic structure and axonal fields encompassing layers I or II (Price, 1973), differ from those observed in the interfascicular neuron (IFN) described here.

Therefore, the present study was conducted first to define the structure of a neuron whose soma, dendrites, and axonal processes are confined to the superficial layer of the PC. Additionally, motivated by the cytological (Somogyi et al., 1982) and immunohistochemical evidence that the occurrence of chandelier cell (CC) candlesticks (CSs) in the rat and mouse cerebral cortex (Inda et al., 2009), respectively, a systematic search for fully impregnated CC was conducted. Characterization of additional cells in the basic circuitry of the PC represents a first, necessary step to elucidate the role of specific neuron phenotypes in the overall PC physiology. To accomplish this, the Golgi technique was utilized, as it has proven to be a reliable tool to fully visualize novel neurons and neuropil in the adult rodent forebrain (Larriva-Sahd et al., 2002; Larriva-Sahd, 2006, 2008; Paredes and Larriva-Sahd, 2010). Since molecular biological studies and genetically modified mice have become indispensable tools for most recent neuroscience research, the adult mouse was elected for the present study. To complement this, adult rat brains from our Golgi collection were utilized to assess species conservation.

\section{MATERIALS AND METHODS GOLGI TECHNIOUE}

Twenty-four satisfactorily impregnated CC's and 12 IFNs (vide infra) were identified from 250 adult CD1 mice brains. Animal manipulation and sacrifice were performed under the guidelines and with the approval of the Animal Research Committee of our Institute, which endeavor to minimize pain and suffering to the 
experimental subjects. All animals were sacrificed by an overdose (90 mg/kg) of pentobarbital. The brain of each animal was dissected, and 3- to 4-mm-thick tissue specimens in either the sagittal or coronal plane were collected. Each specimen was immersed for 20 days in 3\% potassium dichromate and $0.25 \%$ osmium tetroxide dissolved in water, followed by $12-20$ days in an aqueous solution of $0.75 \%$ silver nitrate. The tissue blocks were supported by an external shell of paraffin, and $150-\mu \mathrm{m}$-thick sections were cut at room temperature on a sliding microtome. Finally, the sections were left for $10 \mathrm{~min}$ in $70 \%$ ethyl alcohol, dehydrated in graded solutions of propanolol/water, cleared in terpineol/xylene, mounted, and coverslipped. Additional observations to determine interspecies conservation were performed using our Golgi collection consisting of more than 500 brain specimens from adult rat brain.

\section{DATA ANALYSIS}

Fiber bundles, axons, and their collaterals were reproduced with a camera lucida adapted to a Zeiss Axioplan 2 microscope, utilizing $10 \times, 40 \times$, or $100 \times$ objectives (NA $=0.3,1.0$, and 1.4 , respectively). Drawings from 12 fully impregnated neurons of each type were included in the morphometric analysis (vide infra). The drawings were scanned, digitized, and measured with a personal computer aided by Kontron 400 software. Measurements included the largest and transverse axes of the soma, and areas of dendritic and axonal fields. The frequency of synaptic boutons along the full length of the interfascicular cell (vide infra) axon was determined by direct counting throughout the length of the axon. Bouton incidence was expressed as the number of boutons per length unit (i.e., $10 \mu \mathrm{m}$ ).

\section{RESULTS}

\section{GENERAL DESCRIPTION OF THE PIRIFORM CORTEX}

Figures 1 and 2, reproduced from adult mouse specimens, provide the general organization of the adult mouse PC. As clearly defined by Price (1973), the PC is bounded medially and rostrally by the olfactory tubercle, caudo-medially by the periamygdaloid cortex, and caudally by the lateral entorhinal cortex. Accordingly, the threelayered nomenclature utilized by Haberly and Price (1978) was adopted. Thus, layer I was divided into a superficial, fibrous part (Ia) harboring olfactory bulb afferents and a deep part (Ib) containing association fibers. Layer II is a cell-rich layer whose neuron density increases progressively from the superficial to deep portions. Layer III has a limiting, cell-sparse area that is rich in pyramidal cell axon collaterals and interneurons and a deep portion composed of pleomorphic cells that form an indistinct boundary with the underlying endopiriform nucleus or layer IV.

\section{NEURONS OF THE PIRIFORM CORTEX}

The interneuronal pool of the PC has been described in several earlier accounts; however, to the best of my knowledge neither chandelier cells (PC-CCs) nor interfascicular neurons (PC-IFNs) have previously been described.

\section{CHANDELIER CELLS IN THE PIRIFORM CORTEX}

The triangular or pear-shaped somata of PC-CC lie in layer II or, less frequently (18\%), in the superficial part of layer III (Figures 2 and 3 ), and measure $20.2 \mu \mathrm{m}$ in the long axis. One or two sets of dendrites extend upward and ventrally. The superior dendritic arbor derives
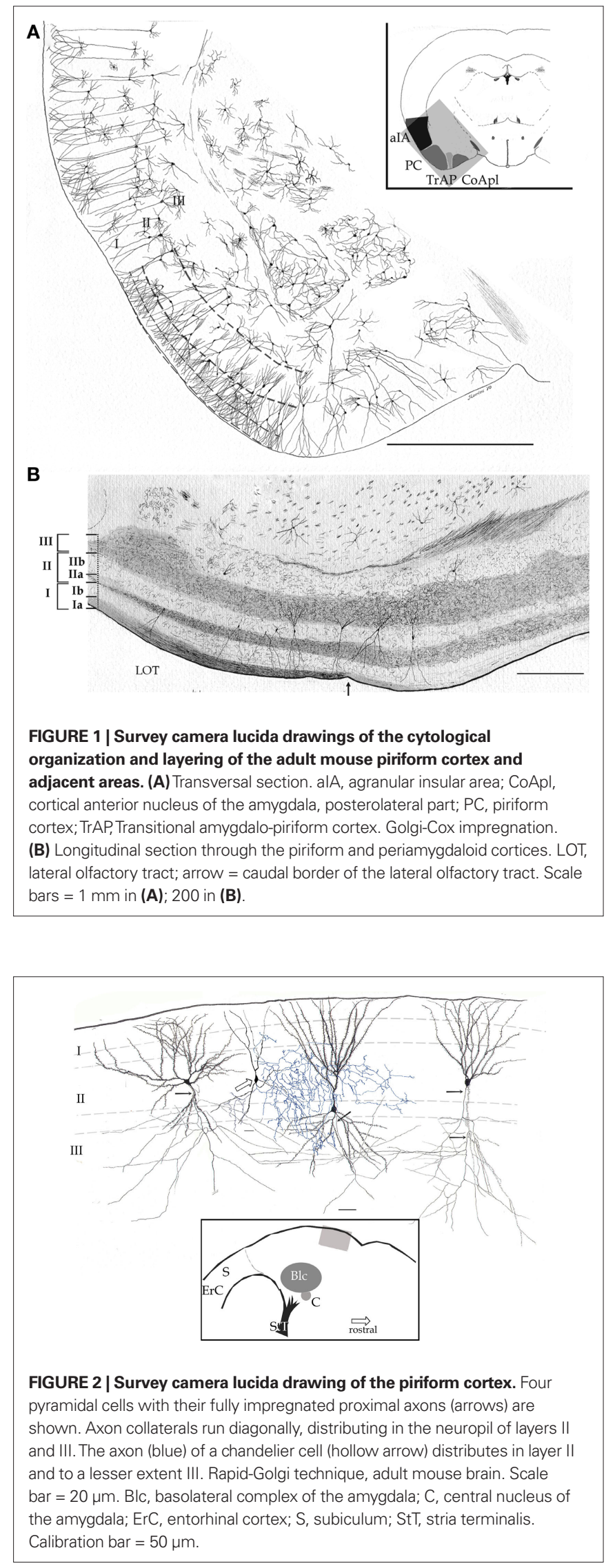


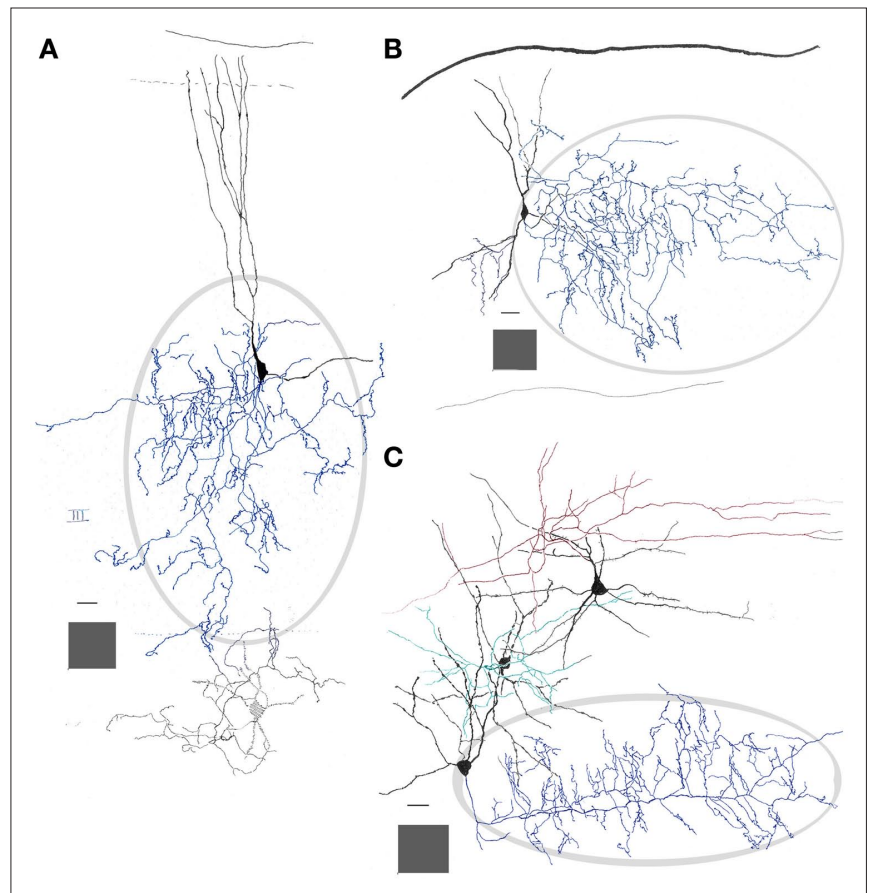

FIGURE 3 | Interneurons in the adult mouse piriform cortex. (A) Dendrites (black) ascend to resolve in sublayer la (dashed). The axon field (blue, encircled) distributes in layers II and III. (B) Chandelier cell whose axon (blue) is polarized anteriorly. (C) Interfascicular neuron with an axon (red) that distributes in layer I, and two interneurons in layer II, a fusiform middle, and a chandelier cell with axons directed radially and rostrally (green and blue, respectively). Adult mouse brain, rapid-Golgi technique. Calibration bars $=20 \mu \mathrm{m}$; squared areas $=250 \mu \mathrm{m}^{2}$.

from a short $(>50 \mu \mathrm{m})$ primary dendrite that divides once or twice, originating secondary and tertiary, often terminal, dendrites. Most ascending dendrites pierce layer I to resolve in its superficial component Ia. Whatever its order, each dendrite exhibits discreet varicosities along its shaft and lacks spines. Although shorter, the same statements apply to basal dendrites that proceed ventrally (Figure 3B). Olfactory fibers in layer Ia interact with apical dendrites in two different ways, via en passage boutons or by descending collaterals which proceed along the neuropil of layers I and II (data not shown). The PC-CC axon (Figures 4 and 5B) arises from the base of a primary dendrite or directly from the soma, and it proceeds caudally for a variable distance (i.e., 125-250 $\mu \mathrm{m}$ ). Then, the parent axon ramifies successively into thinner, secondary and tertiary branches. Unlike the parent axon, axon tributaries exhibit frequent boutons en passage. Axon terminals usually arise from tertiary branches that provide series of vertically oriented boutons that structure the so-called CSs or specific terminal portions (Fairén and Valverde, 1980; Figure 4). Each CS consists of vertical or diagonally oriented series of synaptic boutons united by thin axoplasmic threads. Most CSs encase the initial axonal segment of the neighboring pyramidal neurons; however, spreading of the CS's to the somatic cell area is not uncommon (Figure 5B). As documented earlier (Fairén and Valverde, 1980; De Carlos et al., 1987) each CSs results from the confluence of four or more concurrent fibrils (Figures 4C and 5). The CSs arising from a single PC-CC axon fibril are infrequent, although in the neocortex appear to be

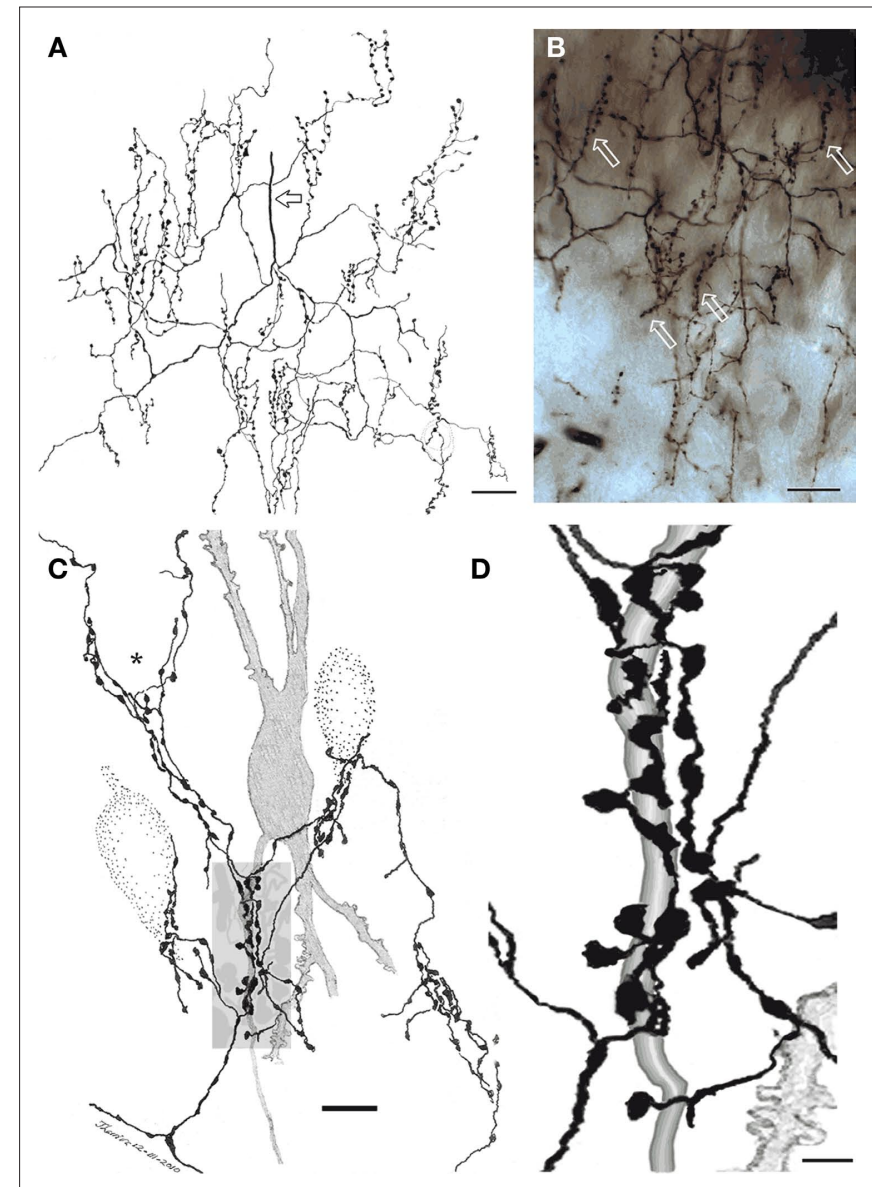

FIGURE 4 | Chandelier cell axon (A) Camera lucida drawing of the proximal part of a chandelier cell axon. Parent axon (hollow arrow) gives rise to several secondary branches that, in turn, resolve into vertically oriented candlesticks. (B) Survey photomontage showing the proximal axon and candlesticks (arrows) from a chandelier cell. (C) Interaction of terminal fibrils and candlesticks with the initial segment of an impregnated pyramidal cell axon (shaded) and those initial segments and soma from three putative pyramidal cells (dotted). Note that some fibrils ascend providing varicosities to the somatic area (asterisk). (D) Enlargement of the candle shaded in (B). Rapid-Golgi technique, adult mouse brain. Scale bar $=10 \mu \mathrm{m}$ in (A,B), 5 in (C).

the most prevalent mode (see Inda et al., 2009). The areas covered by the PC-CC dendritic and axonal (Figure 3) fields average 24,000 and $79,000 \mu \mathrm{m}^{2}$, respectively.

\section{PUTATIVE LOCAL INPUTS TO CHANDELIER CELLS}

In their ascending path, distal dendrites of the PC-CC course through layers II and I. Putative PC-CC afferents derive from the primary olfactory axons and their collaterals in sublayer Ia (Figures 5C,D). In effect, and as described earlier, olfactory axons appear to make contact with distal dendrites (i.e., en passage) or send transverse collaterals whose varicosities appose their shafts.

\section{INTERFASCICULAR NEURONS (PC-IFNs)}

Embedded in layer $\mathrm{I}$ is a neuron that, for its resemblance with the IFNs described elsewhere in the rat anterior commissure (Larriva-Sahd et al., 2002), will be referred to as piriform cortex-interfascicular neuron (PC-IFN). The PC-IFN soma is tri- 


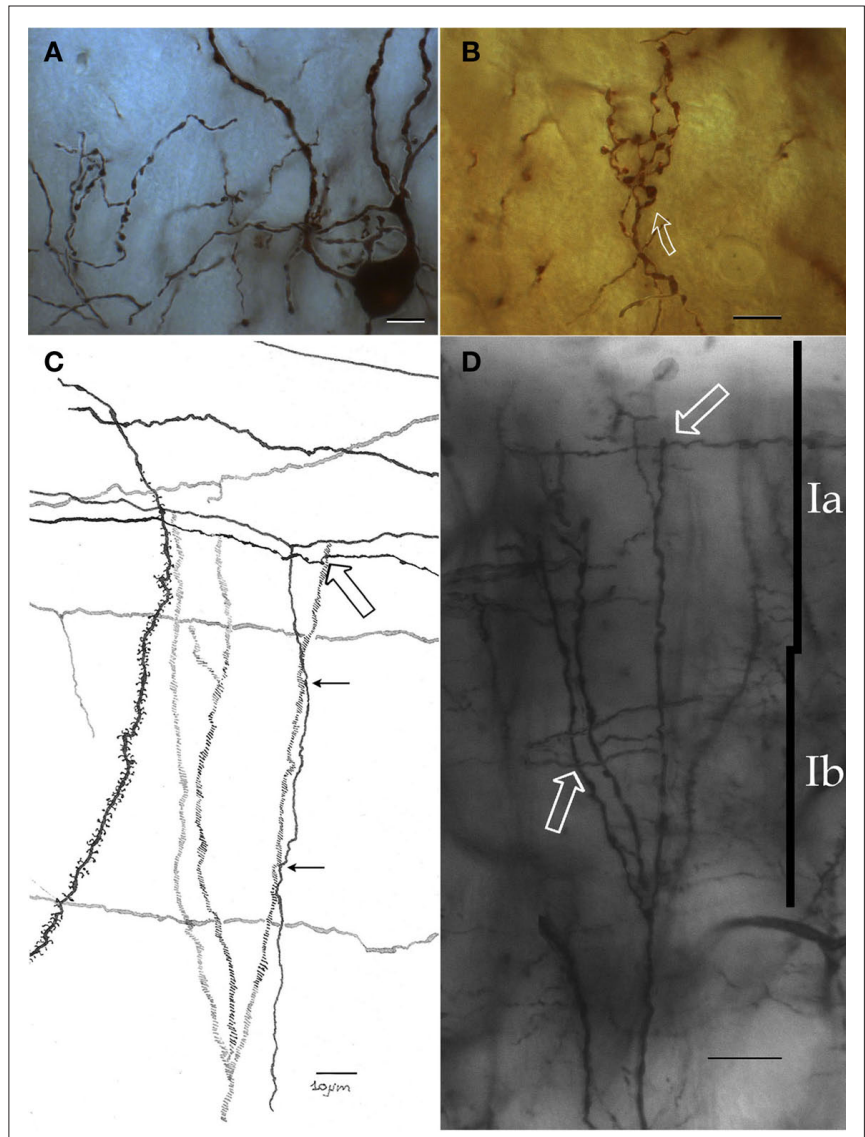

FIGURE 5 | Chandelier cell and its processes. (A) High power micrograph of the soma and proximal processes of a chandelier cell. (B) Fifteen-exposure photomontage of a specific terminal portion of a chandelier cell expanding toward the soma (arrow) to build-up a pericellular nest. (C) Camera lucida drawing depicting distal dendrites of a pyramidal (left) and a chandelier cell (dashed). Note that primary olfactory axons interact with the chandelier cell dendrites by means of boutons en passage (hollow arrow) and descending collaterals (black arrows). (D) Twenty-nine-micrograph photomontage of layer I. Two putative synapses of passage (arrows) with distal dendrites of a chandelier cell. Rapid-Golgi technique, adult mouse brain. Scale bar $=10 \mu \mathrm{m}$ in (A-C); $15 \mu \mathrm{m}$ in (D)

angular or rounded and measures $16 \mu \mathrm{m}$ in its long axis. A PC-IFN lies just medial to the lateral olfactory tract and between layers Ia and Ib. (Figures 6A-C). In Golgi-impregnated specimens the soma of a PC-IFN is rounded or triangular, originating two sets of short primary dendrites that divide once or twice (Figures 6 and 7). The structures of the PC-IFN dendrites differ depending on their location. In fact, ascending dendrites, coursing in sublayer Ia bear varicose shafts, while those descending to layer Ib are usually longer, tend to be smooth, and exhibit only subtle variation in diameter. Thus, the PC-IFN dendritic field is more or less split into two halves, one in each sublayer (Figure 6C). The PC-IFN axon arises from the base of a primary dendrite and proceeds caudally and dorsally. Then, the axon divides repetitively originating long (i.e., $<500 \mu \mathrm{m}$ ) fibrils that run in the opposite direction, always along the rostrocaudal axis. Thus, the frequent axon dichotomization gives rise to a dense, horizontal framework mimicking that observed in the bitufted neurons from the cerebral neocortex (Figures 6 and 7; Ramón y Cajal, 1904). The frequency of axon varicosities (i.e., boutons en passage) along the long secondary axonal branches is relatively high, as they occur, on average, at $2.3 \mu \mathrm{m}$ intervals. This observation of boutons en passage in apposition to terminal dendrites of pyramidal cells suggests the existence of synaptic contacts. The overall appearance of the axon, running horizontally and apposing distal dendrites of pyramidal cells mimics the synaptic interaction observed between parallel fibers and the Purkinje cell terminal dendrites (Ramón y Cajal, 1904). While the dendritic field of an IFN averages $8400 \mu \mathrm{m}^{2}$, the area covered by the axonal field could not be determined because the impregnation of the axon ceases or simply leaves the plane of sectioning.

\section{DISCUSSION}

The results obtained in the present study may be summarized as follows. Two neuron types in layers I and II of the piriform cortex were featured: interfascicular (PC-IFN) and chandelier cells (PC-CC), respectively. The PC-IFN's dendrites are split into the superficial and deep parts of layer I and display structural variations as a function of location. The PC-IFN axon ascends to sublayer Ia to divide dichotomously sending long collaterals to either side in the rostrocaudal axis. In most respects the PC-CC mimics the structure of its neo-cortical counterpart, although subtle differences in the distribution of the dendritic field and axon terminals are found. Neither neuron type was described in the early Golgi literature (vide supra), nor in more recent studies utilizing mice expressing green fluorescent protein in combination with immunohistochemical methods (Gavrilovici et al., 2010; Suzuki and Bekakers, 2010a,b) or with intracellular dye injections (Zhang et al., 2006).

It is well known that neurons in adult mammalian brain are generally refractory to impregnation with the Golgi technique and its variants. In an attempt to improve the neuronal staining quality and completeness in the adult rodent brain, two different, straightforward, strategies were applied, namely longer incubation of the specimens with silver and larger number of assays (more than 250 brains). As it is clear from the present account and our previous studies (Larriva-Sahd et al., 2002; Larriva-Sahd, 2006, 2008; Paredes and Larriva-Sahd, 2010) the adoption of these strategies has enhanced our ability to disclose neuronal fine structure.

There is general agreement that neo-cortical interneurons with different, although specific, structural and neurochemical phenotypes interact in a synergic fashion to, ultimately modulate the overall cortical output of pyramidal cells (Markram et al., 2004). In this context, the discovery and confirmation (Somogyi et al., 1982; Inda et al., 2007, 2009) that PC-IFN and PC-CC, respectively, are native neurons of the adult mouse PC is highly relevant, and these cells should now be incorporated into the prevailing models (Haberly and Sutula, 1992; Gavrilovici et al., 2010) aimed at understanding the role of the PC proper in olfaction and experimental epileptogenesis.

Interfascicular neurons may mediate between primary olfactory axons and pyramidal cells. Neurons entangled by axonal bundles, like the IFNs depicted here, are not uncommon in the mammalian brain (see DeFelipe et al., 2010). Thus, Ramón y Cajal (1904) described a number of medium-sized, spindle-shaped neurons in 
A

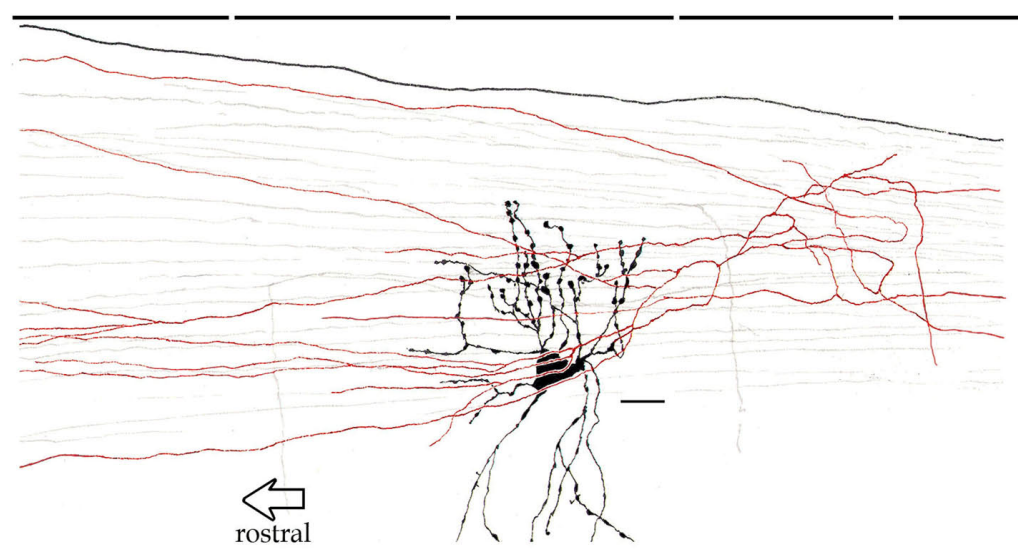

B
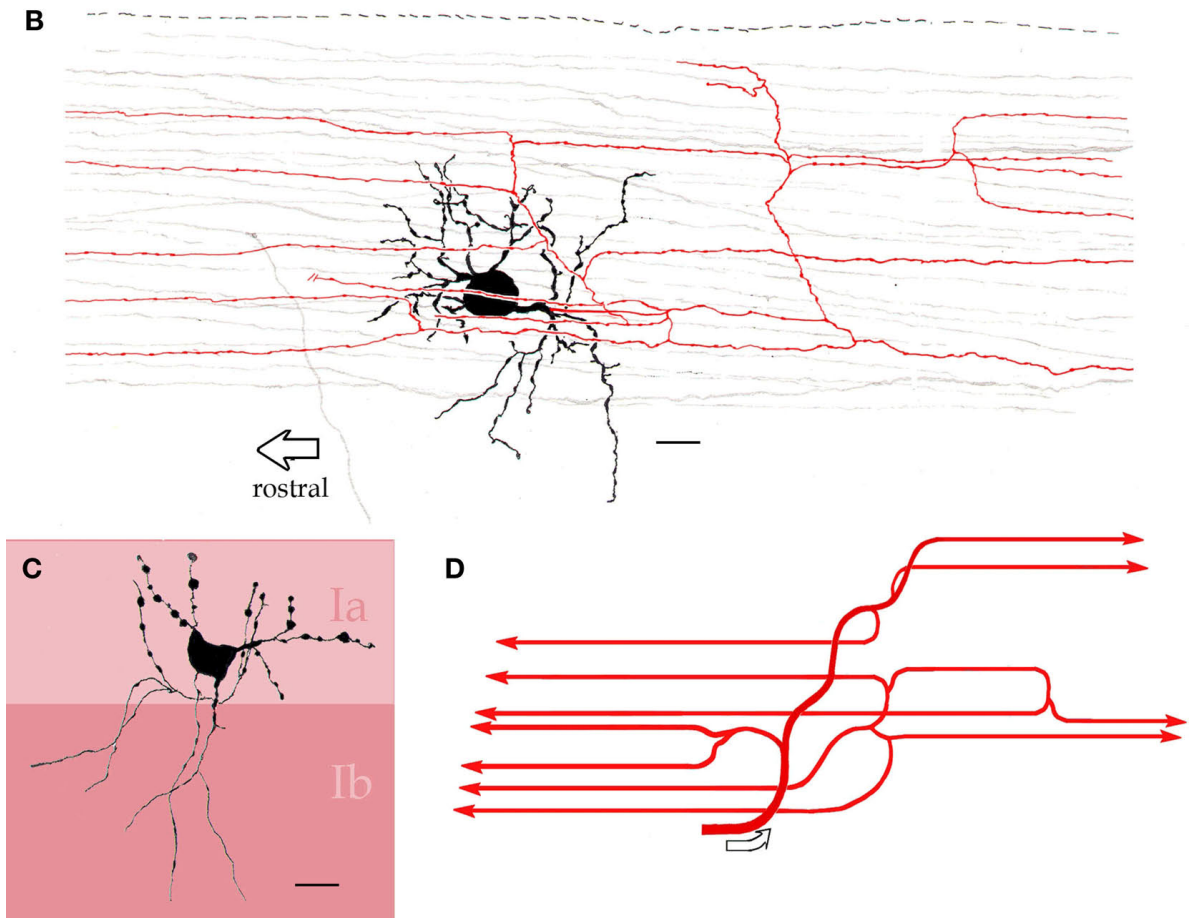

FIGURE 6 | Interfascicular neurons in the piriform cortex. (A) An

interfascicular neuron bearing a triangular-shaped soma gives rise to paired sets of asymmetrical dendrites. The axon (red) divides repeatedly running horizontally.

(B) Interfascicular neuron with a rounded soma. The axon (red) is confined to layer la. (C) Distribution of the dendritic field into sublayers la and lb note the dissimilar structure of dendrites in the two sublayers (la and Ib). (D) Schematic representation of the ramification pattern of the interfascicular neuron axon. Rapid-Golgi technique, adult mouse brain. Scale bars $=10 \mu \mathrm{m}$. the deep cerebellar white matter. Although only a brief account is given in the text, it is clear from his drawing that they correspond to projecting neurons. More recently we performed a systematic Golgi study on the adult rat anterior commissure and found that the cell bodies described earlier (Sturrock, 1977), correspond to both projecting and short-axon neurons (Larriva-Sahd et al., 2002). The fact that these neurons are embedded in commissural axons led us to refer to them as interfascicular neurons (AC-IFNs). Like most neurons located in the white matter, PC-IFNs receive short axonal collaterals from the adjacent fiber bundles. Furthermore, excitatory postsynaptic potentials are triggered in AC-IFNs by electric stimulation of either the adjacent axons (Condés-Lara et al., 2002), or of the basal forebrain areas projecting via the anterior commissure (Condés-Lara et al., 2003). This evidence, coupled with the striking analogies between the AC-IFN and PC-IFN, lead one to suspect that a PC-IFN may represent a cellular link between primary olfactory fibers and pyramidal cells proper (Figure 8). In support of this proposal is the observation that the PC-IFN axon interacts with distal dendrites of pyramidal cells. This interaction between axon varicosities and distal dendrites is strongly suggestive, although not conclusive, for a synaptic interaction (Kalisman et al., 2004).

Chandelier cells control pyramidal cells. A large body of information supports the role of CC in modulating cortical output (i.e., pyramidal) neurons (see Howard et al., 2005; Szabadics et al., 2006; Inda et al., 2009). Thus, the putative physiological role of PC-CC 


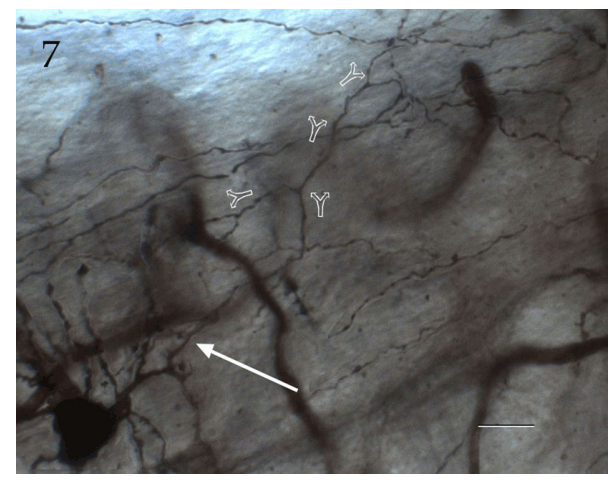

FIGURE 7 | Seventy-six-micrograph photomontage of the proximal axon of an interfascicular neuron. The axon (arrow) divides dichotomously (hollow arrows), and daughter fibrils proceed in opposite directions. Rapid-Golgi technique, adult mouse brain. Scale bar $=10 \mu \mathrm{m}$.

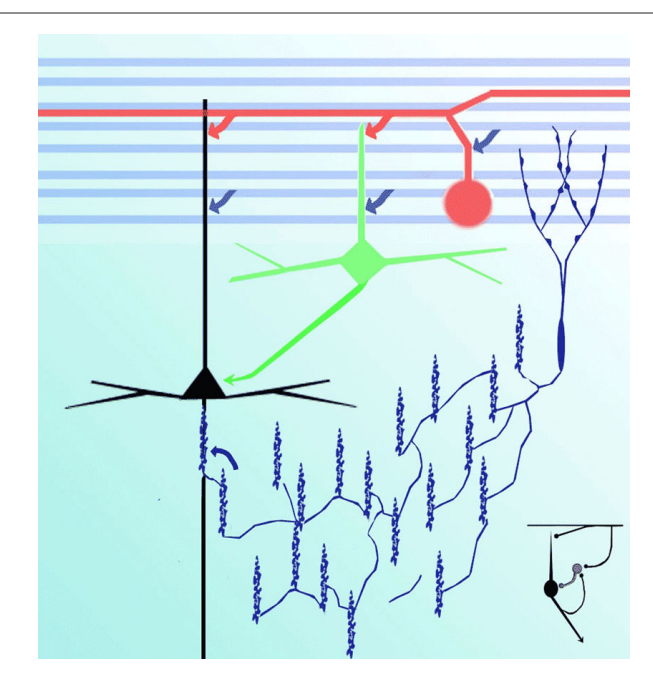

FIGURE 8 | Diagram representing putative interactions (arrows) between olfactory axons (blue) interneurons (green), interfascicular (red), chandelier (deep blue), and pyramidal (black) neurons.

should be commented upon based on analogies and dissimilarities between $\mathrm{CC}$ in the PC and those in other cortical areas. Similarly to CC (Somogyi, 1977; Fairén and Valverde, 1980; Peters et al., 1982; Somogyi et al., 1982; DeFelipe et al., 1985; De Carlos et al., 1987; Inda et al., 2009), PC-CC usually lie in the superficial strata and exhibit nearly identical axonal and somatodendritic structures. Perhaps the most important difference between a CC and a $\mathrm{PC}-\mathrm{CC}$ is that the distal dendrites of the latter pierce layer I from which they appear to receive synaptic inputs. This observation is potentially relevant, as it may imply that certain olfactory inputs arising from mitral cells may exert an influence, mediated by the PC-CC, on the activity of pyramidal cells. In this context, the present and previous observations indicate that CC axons interact with the initial segment of principal cells (DeFelipe et al., 1985). This strategic relation with the site for the initiation of the nerve impulse (Peters et al., 1968) confers on the CC a crucial role for the overall response of the PC. Therefore, the tripartite circuitry involving a glutamatergic-GABAergic-glutamatergic chain (i.e., mitral-chandelier-pyramidal cell) provides a putative cellular substrate for the overall output of the primary olfactory cortex. Indeed, like their neo-cortical homologues, PC-CCs possibly modulate the discharge of principal cells by GABA-mediated excitatory postsynaptic potentials (see Szabadics et al., 2006; Woodruff et al., 2009).

The recent implementation of immunohistochemical techniques has allowed the precise location of the CC candlesticks to be determined throughout the entire mouse cerebral cortex. With this approach it was found that the PC contains the highest numerical density of CSs in the entire cortical mantle (Inda et al., 2009). This evidence agrees with the present observations in that CC somata and their axonal fields are primarily confined to layer II and, to a lesser extent, layer III. Lastly, is the probable significance of the PC-CC candlesticks extending from the initial segment to the neuron perikaryon (Figures 4B and 5A,B), a peculiarity defined earlier in the isocortical (see De Carlos et al., 1987) and ammonic (Somogyi et al., 1983) CC. In fact, the CS structure varies from candles having one or two rows of three to five boutons stung by a thin fibril (i.e., simple CS) to a funnel like complex made up of several rows of boutons, the so-called complex CSs. Although, morphometry cannot be reliably performed in Golgi-impregnated specimens it was noted that, in addition to the overall "tilted" position of CS observed in the PC, there is an obvious higher incidence of CS of the simple type (see Figures $4 A, B$ ). This view matches with the previous quantitative immunohistochemical evidence (Inda et al., 2009). As a major pitfall of the Golgi technique at the light microscopic level is that the observer cannot discern synaptic interactions; thus, intracellular recordings of paired neurons and/or electron microscopic studies are required to define the functional meaning of PC-CC axon terminals interacting with the pyramidal cell soma.

\section{CONCLUSION}

Two neuron types, the IFN in layer I and the CC in layer II or III, were found in the PC of the adult mouse. IFNs lie between sublayers Ia and Ib and bear asymmetrical dendritic processes as a function of location. The IFN axon branches repeatedly and daughter fibrils bearing numerous boutons en passage run rostrocaudally throughout the domain of layer I. The IFN axon varicosities appose distal dendrites of the pyramidal cells laying deeper in the PC deeper layers. CCs lie in layers II and III, in order of frequency, and the axon field distributes in the adjacent neuropil. Confirming previous immunohistochemical evidence, the CC axon forms axon terminals or CSs that appose to the pyramidal cell initial segment. The strategic location of both cell types between the olfactory fibers and deeper pyramidal cells suggest that these neurons may be involved in controlling the out put of the PC proper.

\section{ACKNOWLEDGMENTS}

The author thanks Gema Martínez Cabrera for her careful technical help and Dr. Dorothy Pless for her efficient revision of the manuscript. 


\section{REFERENCES}

Calleja, C. (1893). La Región Olfatoria del Cerebro. Madrid, España: Imprenta y Librería de Nicolás Moya.

Condés-Lara, A., Paz, C., Jiménez, J., Martínez, G., Martínez-Lorenzana, G., and Larriva-Sahd, J. (2003). Electrophysiological responses of interfascicular neurons of the rat anterior commissure to activation from the anterior olfactory nucleus, medial frontal cortex, and posterior nucleus of the amygdala. Brain Res. 982, 288-292.

Condés-Lara, M., Martínez, G., MartínezLorenzana, G., and Larriva-Sahd, J. (2002). Electrophysiological evidence that a set of interfascicular neurons of the rat anterior commissure are neurons. Neurosci. Lett. 323, 121-124.

De Carlos, J. A., López-Mascaraque, L., Ramón y Cajal-Agüeras, S., and Valverde, F. (1987). Chandelier cells in the auditory cortex of monkey and man: a Golgi study. Exp. Brain Res. 66, 295-302.

DeFelipe, J., Fields, R. D., Hof, P. R., Höistad, M., Kostovic, I., Meyer, G., and Rocland, K. S. (2010). Cortical white matter: beyond the pale remarks, main conclusions and discussion. Front. Neuroanat. 4:4. doi: 10.3389/ neuro.05.004.2010

DeFelipe, J., Hendry, S. H., Jones, E. G. and Schmechel, D. (1985). Variability in terminations of GABAergic chandelier cell axons on initial segments of pyramidal cell axons in the monkey sensory-motor cortex. J. Comp. Neurol. 231, 364-384.

Fairén, A., and Valverde, F. (1980). A specialized type of neuron in the visual cortex of cat: a Golgi and electron microscope study of chandelier cells. J. Comp. Neurol. 194, 761-769.

Gavrilovici,C.,D'Alfonso, S., and Pouluter, M. O. (2010). Diverse interneuron populations have high specific interconnectivity in the rat piriform cortex. J. Comp. Neurol. 518, 1570-1588.

Golgi, C. (1885). Sulla fina anatomia degli organi centrali del sistema nervoso. Regio Emilia Riv. Sper. Feniatr. 1, 405-425.
Haberly, L. (1983). Structure of the piriform cortex of the opossum. I. Description of neuron types with Golgi methods. J. Comp. Neurol. 213, 163-187.

Haberly, L., and Price, J. L. (1978) Association and commissural fiber systems of the olfactory cortex of the rat. J. Comp. Neurol. 178, 711-740.

Haberly, L. B., and Sutula, T. P. (1992) Neuronal processes that undelie expression of kindled epileptiform events in the piriform cortex in vivo. J. Neurosci. 12, 2211-2224.

Howard, A., Tamas, G., and Soltesz, I. (2005). Lighting the chandelier: new vistas for axo-axonic cells. Trends Neurosci. 28, 310-316.

Inda, M. C., DeFelipe, J., and Muñoz, A (2007). The distribution of chandelier cell axon terminals that express the GABA plasma membrane transporter GAT-1 in the human neocortex. Cereb. Cortex 17, 2060-2071.

Inda, M. C., DeFelipe, J., and Muñoz, A (2009). Morphology and distribution of chandelier cell axon terminals in the mouse cerebral cortex and claustroamygdaloid complex. Cereb. Cortex 19, 41-54.

Kalisman,N., Siberberg, G., and Markram, H. (2004). The neocortical microcircuit as a tabula rasa. Proc. Natl. Acad. Sci. U.S.A. 102, 880-885.

Larriva-Sahd, J. (2006). Histological and cytological study of the bed nuclei of the stria terminalis in the adult rat. II. Oval nucleus: extrinsic inputs, cell types, neuropil, and neuronal modules. J. Comp. Neurol. 497, 772-807.

Larriva-Sahd, J. (2008). The accessory olfactory bulb in the adult rat: a cytological study of its cell types, neuropil, neuronal modules, and interactions with the main olfactory system. J. Comp. Neurol. 510, 309-350.

Larriva-Sahd, J., Condés-Lara, M. Martínez-Cabrera, G., and VarelaEchavarría, A. (2002). Histological and ultrastructural characterization of interfascicular neurons in the rat anterior commissure. Brain Res. 931 81-91.
Markram, H., Toledo-Rodíguez, M. Wang, Y., Gupta, A., Siberberg, G., and $\mathrm{Wu}, \mathrm{C.}$ (2004). Interneurons of the neocortical inhibitory system. Nat. Rev. 5, 793-807.

O'Leary, J. (1937). Structure of the primary olfactory cortex of the mouse. J. Comp. Neurol. 67, 1-29.

Paredes, R. G., and Larriva-Sahd, J. (2010). Medullary neurons in the core white matter of the olfactory bulb: a new cell type. Cell Tissue Res. 339, 281-295.

Peters,A.,Proskauer,C.C., and KaisermanAbramof, I. R. (1968). The small pyramidal neuron of the rat cerebral cortex. Axon hillock and initial segment. J. Cell. Biol. 39, 604-619.

Peters, A., Proskauer, C. C., and Riback, C.E. (1982). The chandelier cell in the rat visual cortex. J. Comp. Neurol. 206 , 397-416.

Price, J. L. (1973). An autoradiographic study of complementary laminar patterns of termination of afferent fibers to the olfactory cortex. J. Comp. Neurol. 150, 87-108.

Ramón y Cajal, S. (1904). Textura de Sistema Nervioso Central del Hombre $y$ de los Vertebrados. Madrid, España: Imprenta y Librería de Nicolás Moya.

Somogyi,P.(1977).A specific "axo-axonal" interneuron in the visual cortex of the rat. Brain Res. 136, 345-350.

Somogyi, P., Freund, T. F., and Cowey, A. (1982). The axo-axonic interneuron in the cerebral cortex of rat, cat and monkey. Neuroscience 7, 2577-2607.

Somogyi, P., Nunzi, M. G., Gorio, A. and Smith, A. D. (1983). A new type of specific interneuron in the monkey hippocampus forming synapses exclusively with the axon initial segments of pyramidal cells. Brain Res. 259, 137-142.

Sturrock, R. R. (1977). Neurons in the anterior commissure. A light microscopic, electron microscopic and autoradiographic study. J. Anat. 123 751-762.

Suzuki, N., and Bekkers, J. M. (2010a). Distinct classes of GABAergic interneurons provide layer-specific phasic inhibition in the anterior piriform cortex. Cereb. Cortex. 20, 2971-2984.

Suzuki, N., and Bekkers, J. M. (2010b) Inhibitory neurons in the anterior piriform cortex of the mouse: classification using molecular markers. J. Comp. Neurol. 518, 1670-1687.

Szabadics, J., Varga, C., Molinár, G., Oláh, S., Barzó, P., and Tamás, G. (2006). Excitatory effect of GABAergic axoaxonic cells in cortical microcircuits. Science 311, 233-235.

Valverde, F. (1965). Studies of the Pyriform Lobe. Cambridge, MA: Harvard University Press.

Wang, Y., Toledo-Rodríguez, M., Gupta, A., Wu, C., Silberberg, G., Luo, J., and Markram, H. (2004). Anatomical, physiological and molecular properties of Martinotti cells in the somatosensory cortex of the juvenile rat. $J$. Physiol. 561, 65-90.

Woodruff,A., Xu, Q.,Anderson, S. A., and Yuste, R. (2009). Depolarizing effect of neocortical chandelier neurons. Front. Neural Circuits 3:15. doi: 10.3389/ neuro.04.015.2009.

Zhang, C., Szabó, G., Erdélyi, F., Rose, J. D., and Sun, Q.-Q. (2006). Novel interneuronal network in the mouse posterior piriform cortex. J. Comp. Neurol. 499, 1000-1015.

Conflict of Interest Statement: The author declares that the research was conducted in the absence of any commercial or financial relationships that could be construed as a potential conflict of interest.

Received: 09 September 2010; accepted: 27 November 2010; published online: 10 December 2010

Citation: Larriva-Sahd JA (2010)

Chandelier and interfascicular neurons in the adult mouse piriform cortex. Front. Neuroanat. 4:148. doi: 10.3389/ fnana.2010.00148

Copyright (c) 2010 Larriva-Sahd. This is an open-access article subject to an exclusive license agreement between the authors and the Frontiers Research Foundation, which permits unrestricted use, distribution, and reproduction in any medium, provided the original authors and source are credited. 